\title{
Pathways to practice: praxiography and international politics
}

\author{
CHRISTIAN BUEGER* \\ School of European Languages, Translation and Politics, Cardiff University, Cardiff, Wales, UK
}

\begin{abstract}
Political scientists have started to focus on 'practice' as the smallest unit of analysis. Following a broader turn in the social sciences, the practice focus provides multiple advantages, including better conceptualizations of short-term social change, getting closer to the everyday activities of those speaking, writing and doing politics, appropriate conceptualization of agency-structure dynamics, or forms of analysis resonating with other communities than scholarly ones. This contribution asks what the methodological implications of the practice turn are. It is argued that the practice focus does not only imply a certain 'theory' but also a certain methodology. I advance the term praxiography to speak about the forms of analysis produced by practice researchers. I discuss key guidelines of praxiographic research on two levels: first, general research strategies that provide empirical access points, second, guidelines for data collection in the frame of participant observation, expert interviews, and document analysis. I conclude in arguing that although praxiography is context driven, and hence requires to be tailored to the research problem, it is vital to reflect on the methodological repertoire of praxiographic research.
\end{abstract}

Keywords: methodology; practice theory; research strategy; sites; participant observation

\section{From practice theory to praxiography}

What, if any, are the methodological implications of the recent turn to practice? What practical difference does it make for the research process if a researcher draws on 'practice theory'? And what are the strategies available for conducting practice research? This article sets out to address these questions.

Practice theory, a set of conceptualizations implying a focus on practice as the smallest unit of analysis, has been widely received across the social sciences. The term 'theories of practice' was introduced by Sherry Ortner (1984) to refer to recent theorizing in anthropology, notably the work of Pierre Bourdieu. Meanwhile the term is widespread and used much more broadly in various disciplinary contexts. This includes organization studies (Nicolini et al., 2003; Golsorkhi et al., 2010; Nicolini, 2013) or history (Spiegel, 2005) and increasingly political science subdisciplines such as policy studies (Hajer and Wagenaar, 2003; Freeman et al., 2011) or international relations (Neumann 2002; Bueger and Gadinger, 2008; Adler and Pouliot, 2011, 2012). While those employing the term practice theory draw on a

* E-mail: buegercm@cf.ac.uk 
divergent ensemble of thinkers, ${ }^{1}$ they converge on the idea of studying organizations, communities, professions, policymaking, or state interaction as a field of practice. They take social practices which are materially anchored in bodies and artefacts and dependent on implicit knowledge as the smallest and prior unit of analysis.

As has been argued, the practice theoretical vocabulary has several advantages for the study of politics. It allows for inter-paradigmatic dialogue (Adler and Pouliot, 2011), to better conceptualize short-term social change (Neumann, 2002), to get closer to the everyday activities of those speaking, writing, and doing politics (Freeman et al., 2011), to find an appropriate conceptualization of agency-structure dynamics (Adler and Pouliot, 2011), to conceptualize ontological grey zones such as the hybrid zones of governance in-between a private-public or state-non-state relation (Abrahamsen and Williams, 2009), to re-appreciate the role of things and objects (Walters, 2002; Pouliot, 2010), or to develop forms of analysis resonating with other communities than scholarly ones (Freeman et al., 2011).

Practice thinking is well advanced on a theoretical level. With some notable exceptions, much of the discourse on practice theory, however, is driven by intellectual and often abstract (if not even scholastic) concerns. Rather than advancing problem-driven, empirical narratives, the practice discourse appears at times only loosely connected to empirical material and rather motivated by epistemological and ontological contemplation. Although the idea of practice theory tears down the positivist wall which separates theory from empirical practice, quite ironically, only the minority of the partisans of practice theory has offered practical considerations of how to actually conduct practice research. ${ }^{2}$ Somehow the assumption appears to be, if the analytical vocabulary is well advanced, this will do the trick, and there is no necessity to explore the intricacies of doing practice research. This is quite problematic. As Bruno Latour has reminded us:

As soon as a divide is made between theories and what they are theories of, the tip of technoscience is immediately shrouded in fog. Theories, now made abstract and autonomous objects, float like flying saucers above the rest of science, which becomes 'experimental' or 'empirical' (Latour, 1987: 242, emphasis in original).

To avoid practice theory becoming one of Latour's 'flying saucers' disconnected from empirical work, we have to address the associations and connections between practices and the attempts to theorize them. In other words a methodological discussion is required of how theory and practice connect in 'theories of practice'. Turning to practices, as Miettinen et al. (2009) have emphasized, has always been not only a theoretical project, but also an empirical one. Davide Nicolini (2009: 121-122)

\footnotetext{
${ }^{1}$ Including, but not limited to, Pierre Bourdieu, Luc Boltanski, Michel Callon, Michel de Certeau, Michel Foucault, Martin Heidegger, Bruno Latour, Alasdair MacIntyre, Andreas Reckwitz, Theodore Schatzki, Ann Swidler, Charles Taylor, Etienne Wenger and the late Ludwik Wittgenstein.

${ }^{2}$ With some notable exceptions including the authors discussed in the following.
} 
goes one step further when he suggests that in the case of theories of practice, theory and methodology form a 'coherent package' in which a theoretical apparatus has the status of providing 'sensitizing concepts'. Annemarie Mol (2010: 262) considers the need for fundamentally altering our understanding of theory and taking it to be a 'sensitivity' towards the 'multiplicity of reality' and as a 'mode of engaging with the world'. Even social theorist Andreas Reckwitz (2008: 195), otherwise rather inclined towards abstract reasoning, admits that practice theory is more than theory and entails a distinct 'search and find strategy'. Following these arguments the discussion of methodology (or better: the practice of doing practice research) is at the heart of the practice theoretical project. It is not an add-on to the development of vocabularies. To the opposite: it is what the so called 'practice turn' is all about.

In this article I set out to discuss the 'practice of doing practice theory driven research'. I follow Annemarie Mol's (2002) suggestion and employ the term praxiography to signify the practice of doing practice theory driven research. Praxiography is first a useful term since it takes up the argument that the turn to practice is not primarily about theory, but about the practice of doing research. The term clearly indicates this shift in perspective. It clarifies that practice theory requires a distinct methodology. Second, the term emphasizes that practice theory driven research has many resemblances to the concerns expressed in ethnography, yet, it differs in focus and emphasis. While 'graphy' signifies the common task of describing, recording and writing about a distinct phenomenon, in difference to ethnography, praxiography is less interested in ethno (culture) but in praxis (practice). Praxiography entails a certain style of doing analysis and requires coping with a set of distinct problems. Many of these problems are familiar and have been discussed in ethnography (or debates on actor-network theory). This includes, for instance, access to and the selection of data. Others are more specific to the challenge of writing about practices, such as how to cope with the tempospatial dispersion of practices and their unruliness or how to unravel the embodied, tacit type of knowledge that underlies a practice.

My discussion will be first of all appealing to those interested in writing a praxiography. My goal is to outline a set of problems and challenges that the majority of praxiographers will face, to discuss strategies of coping with them and to reflect on procedures of data production. Such a discussion fills a major gap in the present practice turn discourse. My discussion takes many of its examples from the study of international politics. Yet, my argument is not confined to the disciplinary context of International Relations. My concern is with outlining some general reflexive guidelines for fathoming how to do praxiography and the choices it implies. The discussion, however, does not provide a 'manual' or 'template' that can be simply followed. Every praxiographer will have to make his or her own choices in the conduct of his or her own research and the context of the practices studied. Praxiography is not a singular strategy. It has to be tailored to the problems and practices at hand. It requires mixing and blending different strategies into each other or inventing new ones in response to the material studied. Moreover, it is one of the 
core messages of practice theory that knowledge and practice are intimately linked. Hence, doing a praxiography requires 'learning by doing', that is, actually writing one.

On a secondary level this paper is also motivated by the observation that the discussion of methodology, research strategies and methods within Political Science and International Relations is often too narrow. This centrally concerns the discussion of methodology and styles of reasoning and researching within the interpretative and qualitative (or constructivist) tradition. While positivist methodology and research technology, notably statistical analysis, is well advanced, constructivists, when they discuss methodology, tend to place too much emphasis on philosophical debates, rather than reflecting on practical research strategies and methods. ${ }^{3}$ Among constructivists in political science, philosophy of science is often heralded as the silver bullet. The consequence is a lack of reflection on the practice of research - a discussion that tends to be left to other disciplines (including mathematics, sociology or anthropology) - discourses which then have to be imported and translated under considerable cost.

My discussion is structured in three sections. I begin in reconstructing what theories of practice are a theory of: I explore the core ideas of the concept of 'practice'. This is followed by a review of the main difficulties and challenges of researching practice. Then I introduce three core strategies of praxiography. I review the strategy of investigating sites, of studying controversy and of following concepts, objects and technologies. I end in stressing that these strategies are not necessarily exclusive, but can be productively combined in research. While each strategy provides a different empirical access point, they can be blended into each other. I move to the question of what techniques are available to gather knowledge about practice. I discuss three: participant observation, (expert) interviews, and document analysis.

\section{Problems of praxiography}

The core claim of praxiography is that 'the social', 'the cultural', and 'the political' are based primarily and in the last instance in implicit knowledge and meaning. The focus of praxiographers is on implicit or tacit knowledge, that is, a type of knowledge which is rarely verbalized and is hence not easily readable from signifiers, speech, and discourse. Practices are taken to be the mediator and carrier of such knowledge. Hence to understand social and political order, praxiography suggests studying practices which constitute these orders of knowledge. For praxiography explicit knowledge such as norms or rules - and articulated meaning - for instance through speech - are of secondary relevance. Explicit knowledge and articulated meaning requires and depends on practice. Practice in this sense is simply ontologically prior.

\footnotetext{
${ }^{3}$ See paradigmatically Vincent Pouliot's (2007) discussion of 'sobjectivism' which focuses exclusively on philosophical aspects. There are, however, some notable exceptions which also indicate that the tides are turning. See for instance Aradau et al. (2014).
} 


\section{What are practices?}

What are practices? Praxiographers understand practices as meaningful, regulated bodily movements, which depend on a related implicit incorporated knowledge. Since the majority of practices deal with artefacts (e.g. writing requires a pen and paper), practices are often routinized patterns of behaviour using artefacts. Often a certain way of doing is inscribed into artefacts and they hence can equally be considered as carriers of practice. The core argument for considering practices to be basic or foundational is in the claim that they are anchored materially, primarily in bodies but also in artefacts. Bodies and artefacts give practice materiality.

Practices are then combinations of (1) forms of bodily and mental activities, (2) artefacts or 'things' and their use, and (3) a background, implicit or tacit knowledge which organizes the practice and gives meaning to it. Figure one represents these three dimensions in the form of a triangle.

Praxiographers have advanced different ways of conceptualizing the knowledge that practices depend on. In Reckwitz' (2002: 249) formulation this knowledge is 'in the form of understanding, know how, states of emotion and motivational knowledge'. Theodore Schatzki $(2002,2005)$ advances a concept of background knowledge which is composed of items of three different sorts: (1) practical understandings (know-how), (2) rules, and (3) a teleological(-affective) structuring. He understands rules as 'explicit formulations that prescribe, require, or instruct that such be done, said, or the case' (Schatzki, 2005: 471). A teleoaffective structure 'is an array of ends, projects, uses (of things), and even emotions that are acceptable for participants in the practice' (Schatzki, 2005: 471). Over his work Bourdieu (e.g. 1977) advances the concept of 'habitus', which is the implicit knowledge inscribed in bodies and is more of an individualized personal ensemble, and the concept of 'doxa', which is the implicit knowledge specific for a field or social formation. Rouse (1996) suggests that implicit knowledge is organized in the form of narratives, which carry the practices and provide stability for them over time. Irrespective of these different conceptualizations, praxiographers make clear that they are primarily after this background knowledge which gives the social and political its stability and provides for meaningful action.

\section{What is the methodology of praxiography?}

As Reckwitz (2008) elaborates, praxiography is much more than only a conceptual apparatus and an ontological vocabulary. It is more than a philosophical and theoretical programme. It is a research approach; it entails a distinct 'search and find strategy', a form of reconstruction and a way of dealing with empirical material (Reckwitz, 2008: 195). Praxiography wants to reconstruct meaning and is hence an interpretative and qualitative research approach. Miettinen et al. (2009) observe (from an organization studies perspective), that praxiography is fed by a range of methodological considerations as they have been presented in debates around pragmatism, ethnomethodology, ethnography, activity theory, or actor-network theory. Indeed these sets of tools and philosophical presuppositions are (in the frame of the 


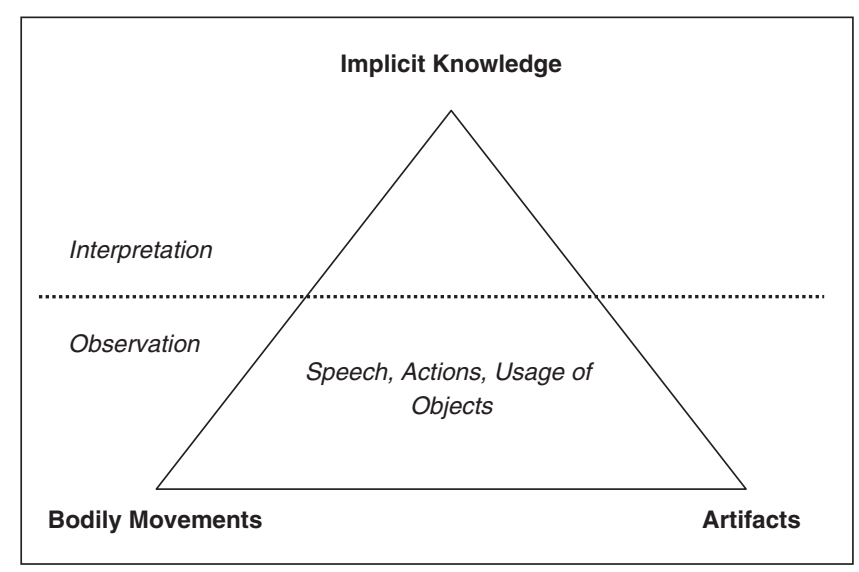

Figure 1 Observing practices.

turn to practices, but also independently from it) increasingly translated to political science. ${ }^{4}$ Arguably this is a heterogeneous set of approaches, yet the differences are in procedure (e.g. in sequencing or prioritizing research techniques) and emphasis (e.g. concerning the status of artefacts), rather than of principle.

If we return to the three core elements of practice, implicit knowledge, bodily movements and artefacts, we can identify the core concern of praxiography in reconstructing the meaning of these elements and their interplay. Praxiography is on the one side very easy, on the other quite intricate. It is straightforward since bodily movements and artefacts are often readily accessible and directly observable without the need for intricate interpretation procedures or major construction efforts. Studying movements and the use of artefacts is to start research with what is immediately accessible. The researcher needs to observe, watch, listen, and record. On the other side, the praxiographer is interested in what is by definition not readily available: the implicit background knowledge. To reconstruct background knowledge requires interpretation. As indicated in figure one praxiography operates on two levels, a level of observation and a level of interpretation. What makes praxiography tricky is this double structure of observation and the interpretation of implicit structures of meaning (Figure 1).

\section{Interpretation: how to reconstruct background knowledge}

Implicit meaning is not immediately accessible; it needs to be accessed indirectly. To reconstruct implicit knowledge will require considering articulated meanings, utterances, actions or the handling of objects and artefacts. The praxiographer

\footnotetext{
${ }^{4}$ See for instance on pragmatism Hellmann (2009), Kratochwil (2007), Kratochwil and Friedrichs (2009), or Franke and Weber (2011), on ethnography see De Volo and Schatz (2004), Vrasti (2008), or Eck1 (2008) and on actor-network theory see Walters (2002), Srnicek (2010), or MacKay (2007).
} 
requires finding and identifying data which allows for conclusions on implicit structures of meaning. Much of this data will be found in articulated meaning, such as in explicit rules, classifications, cultural codes, metaphors, speech acts, representational practices, or discourse. Although praxiography claims that explicit articulated meaning is only of secondary relevance, in doing praxiography, the researcher de facto often needs to primarily draw on this data. Analyzing such data brings praxiography in close relationship to discourse analysis (Reckwitz, 2008). Although both styles of researching have often been seen as opposing each other ontologically, in the conduct of the practice of research, many of their interests and objectives (to analyse articulated meanings) de facto intersect. In contrast to discourse analysts the praxiographers will, however, always attempt to gather first hand observations of speech, and as discussed in the following sections, only consider documents in so far, as sayings and doings cannot be observed directly. Under such conditions praxiography analyzes documents - including manuals and handbooks - ego-documents - such as letters and auto-biographies -, or artefacts which record practice - such as videos, paintings, or architecture. While discourse analysts treat such data as 'monuments of discourse', the praxiographer interprets them as documents which relate to a bodily material practice outside of the text itself but to which the text is related (Reckwitz, 2008).

The problem of access to implicit knowledge cannot be solved, but coping strategies are available. The praxiographic research process is one of turning implicit knowledge into explicit. This implies a high degree of interpretation. Yet, it does not necessarily implicate forcing meaning upon the practices studied. The solution of praxiography is to attempt to identify moments in which participants in a practice tend to articulate implicit meaning themselves.

\section{The strategy of looking down}

The interpretative process of praxiography is what has been dubbed a 'strategy of looking down' (Kwa, 2002; Law, 2010). Much of social science has attempted to 'look up'. It assumes that the system, the social whole, is knowable and that it is controllable. Looking up implies to continuously search for coherence and regularity. The attempt is to generalize, to formulate claims which are valid and coherent across a micro and macro level. Concepts and vocabularies are understood as abstract symbols that assist in finding coherence, regularity and make the social whole knowable. Hence, the strong focus on epistemology. The strategy of looking down takes the opposite direction. Rather than searching for the big system and the abstract principles, looking down is to apprehend the local and the non-coherent. No natural scale of micro and macro is suggested, rather the making of levels is studied as the outcome of the local. Concepts and vocabularies are then treated as part of the social and they are seen as embedded in context, time and space. Rather than searching for coherence and regularity the objective is to sense the mundane materiality of life and to 'feel around' in local contexts. Praxiography then faces two 
challenges: First, how to cope with the problem of scale and formulate statements which are relevant beyond an immediate local context; second, how to address contingency and deal with the unruliness of practice.

\section{The problem of scale: transcending micro, meso, and macro}

Praxiography is looking down, it is the microscopic study of situations in which bodily movement and artefacts are observed to decipher background knowledge. Yet, the majority of praxiographers are interested in large scope formations conceptualized, for instance, as 'fields', 'communities', 'assemblages', 'knowledge orders', or 'structures'. Fields of practice, such as the art of policymaking, state administration, education, the global financial market, the diplomatic profession, regional security communities, US foreign policy, or UN peacebuilding have been the object of study of praxiographers. Yet, how is it possible to pursue the goal of understanding formations of such scope, often of 'transnational' or 'global' reach, through a study of something that appears to be as small as practice?

The first answer from praxiography is that the concept of practice is open in scale. To study practice does not prescribe a scale in time or space. Hence it is equally appropriate to study a seemingly large scale, such as the practice of fighting wars throughout history, as it will be meaningful to study smaller scale, such as the Afghan practice of ambushing, or an everyday interaction. Using the concept of practice does not suggest a distinct level of aggregation. As Nullmeier and Pritzlaff (2009: 10) remark, this is because the borders of one practice to another are undetermined. Practices are often nested in each other, their inter-relation is complex.

The second answer is that the study of practice does not necessarily entail to study all of the complexity of practice. As argued by Schatzki (2005), often it will be meaningful to develop overviews of fields of practice. This does not necessarily or always require tracking and registering 'the potentially labyrinthine complexity' (Schatzki, 2005: 477). In many cases it is desirable and feasible to provide overviews referring not to the details of practice but to larger formations. For Schatzki such overviews operate in a higher degree of abstraction, 'in the sense of extraction from a fuller reality' (Schatzki, 2005: 477). ${ }^{5}$

The third, and maybe most important, answer is that praxiographers - notably those emphasizing relationalism - reject the idea of natural scales. Micro-macro or local-global distinctions are not considered as meaningful ontologies. 'The orthodox language of social science [...] carves up phenomena into three levels: from the very micro (what people say and do); to the meso (routines); to the macro (institutions)' (Miettinen et al., 2009: 1309). Praxiography aims to reconceptualize the ideas of such levels. Indeed, there is no thing such as micro, macro, local, or global. These are

\footnotetext{
${ }^{5}$ For Schatzki (2005), practice-arrangements are nested in each other. He considers different scales: meshes are embedded in bundles, which relate to bigger nets of bundles, which lead us to confederations of nets and up to one gigantic metamorphosing web of practices and orders.
} 
constructs of social scientists who adopt strategies that try to make them so. Praxiography hence aims at allowing 'the transcendence of the division between such levels, such as that we are able to understand practice as taking place simultaneously both locally and globally, being both unique and culturally shared, "here and now" as well as historically constituted and path-dependent' (Miettinen et al., 2009: 1310).

Praxiographers have on the one side transcended levels through concepts. Knorr-Cetina (2005) for instance develops the paradoxical concept of 'global microstructures' to stress how the global and local, the structural and the ephemeral are merged. ${ }^{6}$ Others turn the question of how levels are made into an explicit empirical question. They study the practice of making levels and ordering the world into scales (e.g. Latour, 2005; Tsing, 2005). The research strategy of studying sites, which I shall discuss below, explicitly addresses this concern.

\section{The problem of routine}

Praxiography is interested in social change. Indeed for some the capacity of praxiography to better conceptualize and study social change is one of the main reasons to turn to it (Neumann, 2002; Spiegel, 2005). Without doubt the worlds described by praxiography are much more contingent than the worlds driven by causal laws, or logics of interests and norms. However strong the emphasis on contingency in the form of rearrangements or innovation in practice is, change is also an intricate problem for praxiography. Practices are repetitive patterns, but they are also permanently displacing and shifting patterns. Practices are dispersed, dynamic and continuously rearranging, but they are also reproducing clusters. This places the praxiographers in the midst of a continuous tension between recognizing the dynamic, continuously changing character of practice on the one side, and the identification of stable, regulated patterns, routines, and reproduction on the other. The problem of routine escapes easy solutions. It can only be addressed by a continuous reflexivity towards the concomitance of the emergent, innovative side of practice and the repetitive, reproducing one. ${ }^{7}$ On a conceptual level praxiographers have aimed at addressing this tension by distinguishing between minor adjustments and major ruptures in practice (e.g. Schatzki, 2002). A minor adjustment refers to the principle of indexicality (Nullmeier and Pritzlaff, 2009) and the fact that any new situation requires adjusting and re-arranging the practice in it. A major rupture refers to those moments in which practices fully break down. This can be because of their failure, the rise of a newly emergent practice, the invention of a new object, or a new encounter between practices. One major methodological response to this problem has been to explicitly focus on moments of rupture and crisis to learn about practices which are adjusted, replaced or newly emerge in such contexts.

\footnotetext{
${ }^{6}$ Other such concepts include the concept of 'Global Assemblages' (Collier and Ong, 2005) or the notion of 'Actor-Networks' (Latour, 2005).

7 The majority of praxiographers, however, tend to emphasize either the emergent or the repetitive character of practice (Bueger and Gadinger, 2008).
} 


\section{Symmetry: a summary}

In summary praxiography is on the one hand a straightforward affair: it is to observe and record the movement of bodies and the handling of artefacts in situations. Yet, on the other hand it also involves the very intricate task of drawing on these observations to interpret the implicit orders of knowledge that inform the practices. How do we get after the background knowledge? This question remains the main challenge of praxiography. Moreover, praxiography aims at transcending scales and levels. It is a strategy of looking down and studying up. Yet, how to transcend scale? And how to cope with the concomitance of the emergent, innovative side of practice and it's repetitive, producing one? In the following I discuss a range of research strategies and methodological techniques to address these questions. These strategies are not answers or solutions to the conundrums of praxiography in any straightforward sense. But they are coping strategies.

\section{Praxiographic research strategies}

Three research strategies that respond to the challenges of praxiography are discussed below. Each strategy has its own strength and better responds to some of the problems outlined. The strategies are not necessarily exclusionary, and many praxiographers mix and blend them into each other. However for the sake of clarity I here discuss them separately. In essence these strategies are means of organizing research and provide reasonable ideas of where to start looking. In discussing these strategies, I do not claim that these represent the full set of strategies available. Indeed there are others, ${ }^{8}$ and some research projects will require the invention of entirely new ones. I introduce the 'strategy of zooming in on structure-making sites', then the 'study of crisis and controversy', and end by outlining the 'strategy of following'.

\section{Sites}

A number of praxiographers have suggested a focus on sites. Schatzki (2002) even suggests that praxiography should be understood as a 'site ontology'. Now a site is in essence a certain locale, a place composed of practices and material arrangements. It can be an organization, a unit or a distinct geographical place hosting a dense ensemble of practices. To consider a site as the primary starting point for praxiography notably allows for transcending scale if emphasis is on those sites in which structure and order is made.

The focus on sites has been a crucial move to transcend levels and scales of the social. As Marcus notes: 'There is no global in the local-global contrast [...].

\footnotetext{
8 This includes for instance the study of how practices are learned and actors are introduced to practices, which is a strategy that is highlighted by those drawing on the community of practice approach (for a discussion see Lave and Wenger (1991) and Freeman (2007)).
} 
The global is an emergent dimension of arguing about the connection between sites' (Marcus, 1995: 99). It is useful to cite Bruno Latour here at some length, as he expands on this idea eloquently:

'Macro no longer describes a wider or a larger site in which the micro would be embedded like some Russian Matryoshka doll, but another equally local, equally micro place, which is connected to many others through some medium transporting specific types of traces. No place can be said to be bigger than any other place, but some can be said to benefit from far sager connections with many more places than others. This move has the beneficial effect to keep the landscape flat, since what earlier, in the pre-relativist sociology, was situated 'above' or below remains side by side and firmly on the same plane as the other loci which they were trying to overlook or include. What is now highlighted much more vividly than before are all the connections, the cables, the means of transportation, the vehicles linking places together' (Latour, 2005: 176).

To take an illustration from international politics: the UN Security Council, with its 15 members and its meeting chamber is certainly not larger, or macro in a physical sense, than, for instance, a UN peacekeeping mission, with hundreds or even thousands of employees. Yet, what makes the UN Security Council appear larger, or more macro, is the multiple connections it holds to other sites, such as state embassies, the UN secretariat, regional organizations, international lawyers, or the command and control centres of peacekeeping operations. To hold these connections stable, however, multiple traces and devices are necessary. Such devices are for instance documents, such as resolutions and declarations, produced in the Security Council and disseminated globally.

The key idea expressed here is that a structure becomes structural, and order becomes orderly by practices of structuring and ordering. It leads to the investigation of the production sites of structure, that is, the sites in which successful ordering takes place. This foregrounds the query of 'Where is structure and order actually produced?' Crucial for sites with high structural effects (or high ordering capacity) are the relations they hold to other elements. As Latour clarifies:

If you cut some underlying structure from its local application, nothing happens: it remains there in its mysterious empyrean; if you cut a structure-making site from its connections, it simply stops being able to structure anything (Latour, 2005: 176).

A case of structure-making sites that has become crucial in developing the research strategy of sites has been the scientific laboratory. In what has become known as 'laboratory studies' or 'laboratory constructivism,', scholars were able to demonstrate that the worlds manufactured in laboratory sites were far more consequential than disclosed only by the actual geographical boundaries of a laboratory site. These results have meanwhile been generalized into a more general notion of structure-making sites.

9 See Knorr Cetina (1995) for a summary. 
Scholars, such as Latour (1987) have extensively shown through ethnographic research that the microworlds and entities manufactured in laboratories did not only have a life inside the walls of the laboratory. The intriguing feature of laboratories is to transcend any inside and outside and as such create through their interventions stable entities that can circulate to other locations. In laboratories then stabilized objects are created and sets of standardized practices are packaged to travel. Laboratories were defining and distributing roles which might be social, political, or technical in character. In other words, laboratories were sites creating structure; they were ordering the world.

Science studies scholars (e.g. Latour, 1987; Rouse, 1987; Knorr Cetina, 1999) have developed these results from laboratory studies further into a more generic model of structure-making sites. Latour has aimed at generalizing the findings of laboratory studies in dropping the laboratory metaphor and introducing the notion of 'centres of calculation'. Such centres were for Latour sites 'where information is being created, collected, assembled, transcribed, transported to, simplified and juxtaposed in a single location, where everything that is relevant can be seen' (Law, 2003: 8). For Latour, in centres of calculation traces can be explored which stand, in a single place, for a whole set of events and processes distributed through time and space. He suggested that there is a circular flow out from the centre, which can be commands or demands, and a flow back to the centre, in the forms of representations and other returns. The centre becomes a centre as the result of this asymmetrical configuration of a structure and the flows that move along it. The efforts of all elements in a structure become directed by, and indeed belong to the centre, 'which comes to stand for and articulate them all' (Law, 2003: 8). Latour's metaphor of centres of calculation has travelled widely and has been adopted in different disciplinary contexts including political science. Brendan Luyd (2008) for instance interprets the colonial library as a centre of calculation. Saul Halfon (2006) understands the surveys of demographics as a centre of calculation for global population policy. Lidskog and Sundqvist (2002) see the global environmental regime as connected through environmental science, which they interpret as centre of calculation. These are examples that highlight the productivity of investigating ordering sites.

The notion of centres of calculation has however often been restricted to cover primarily scientific activities (in the closer sense). In the just introduced examples it is scientists or librarians who do the ordering work. Latour (2005) clarifies that science in the closer sense is indeed a very good example of how apparently small local sites can produce (macro) structural effects. Yet it would be more than misleading to restrict the idea of structure-making sites to science and see only scientists as being capable to do so. Indeed similar or even better examples are instances such as bureaucratic units or military command and control centres which perform such functions. The illustration of the UN Security Council points to such a site in international politics.

For clarification Latour proposed a new term. To designate laboratories and centres of calculation in this broader sense, he put forward the term 'oligopticon' as 
the generic term, and left laboratory and centre of calculation to those sites where literal and not simply metaphorical laboratory experiments are conducted and calculations are made possible (Latour, 2005: 181) ${ }^{10}$ To move from laboratory to oligopticon is a generalization that assists in capturing the diversity of ordering sites. Moreover, it clarifies that ordering sites are not the all encompassing centres that integrate and control everything. Ordering sites, oligoptica, have narrow, but powerful and robust views, and so are their effects.

In summary, the site strategy suggests we focus attention on centres of calculation and oligoptica as those sites where structure is made and ordering practices take place. This raises the question of how these sites can be identified. Latour (2005) suggests that an identification of oligoptica is best done through a general mapping of flows and traces to identify the nodal points which are the centres. An indicator for a structure-making site is that these are well connected. Sometimes the identification of an oligopticon is fairly easy. For instance, if we are interested in the practices of a peacekeeping mission it is simple to identify the mission's command centre as a potential oligopticon. The situation is more intricate if we are interested in governance. Many connections might barely be visible and there will be more than one centre. Often this will then require the investigation of more than one site, we will have to conduct 'multi-sited research' (Marcus, 1995).

The site strategy hence suggests the following steps: first, identify the major structure-making and ordering sites. Second, track by which practices they order and how they are connected to other elements and sites. Third, reconstruct the kinds of orders they aim at establishing and stabilizing.

\section{Crisis and controversies}

Constructivist IR scholarship has long found value in studying moments of crisis and controversy to understand knowledge, notably the impact of new knowledge (or 'ideas'). ${ }^{11}$ For instance, Keohane and Goldstein (1993) have advanced such an agenda in a classical volume. As they suggest, moments of crisis present windows of opportunity to introduce and feed new ideas into policy. Norm-oriented constructivists also increasingly highlight the importance of zooming in on moments where norms are contested and disputes arise. As, for instance, Sandholtz (2008) suggests, in these situations normative change occurs. Disputes about the meaning or the applicability of a norm imply that norms have to be re-adjusted or novel ones need to be developed. The arguments of praxiographers are related, when they suggest studying moments of crisis, disputes or controversies. There are two main praxiographic arguments for focusing on crises. First, in such moments implicit knowledge often becomes explicated and articulated. Participants in a practice

\footnotetext{
${ }^{10}$ For a discussion of how problematic the extension of the laboratory metaphor is and why it is unproductive to conflate all sorts of sites under the notion see Guggenheim (2012).

11 See Widmaier and Blyth (2007) for a summary of the discussion of crisis as a moment of change, Hellmann (2009) for the pragmatist position, and Howarth (2009) for the discourse theoretical position.
} 
discuss and argue about whether the new situation can be accommodated into existing practices, adjustments need to be made or new practices need to be introduced or invented. Second, moments of crisis present situations of change. Studying such situations hence allows learning about old practices (since implicit knowledge is articulated) as much as about newly emerging practices.

What is a moment of crisis? Moments of crisis are often associated with distinct events. For instance, 11 September 2001 has become a crucial example of a day that marked a major rupture in the structures and practices of international security. Yet, a focus on a day or the single major event is too narrow an understanding. For instance, a moment of crisis might well be induced by a series of events or a larger process. A paradigmatic example in this regard is the end of the cold war, which arguably was not triggered by events on the day of 9 November 1989, but by a series of events and developments. Hence, it makes sense to rely on a wider understanding of moments of crisis.

A useful proposal in this regard is to understand crisis as those processes in which structures or routines fail to provide for what is necessary for proceeding by everyday routine, to cope with a new object or to solve a distinct problem of the public. Hence a crisis moment presents a situation in which structures and routines fail. Everyday action cannot simply proceed. To return to the example of the terrorist attacks of September 11th, on this and the following days it was recognized that the political structures and routines failed to prevent what should have been prevented. Existing structures and routines were insufficient to prevent a major transnational terrorist attack. Hence, new practices of prevention, protection, and control were introduced.

Policy analysts David Laws and Martin Rein dwell on such an understanding when they give the following interpretation of controversies:

Controversies include such moments of doubt when accepted stories are challenged or events upset conventional accounts and an indeterminate situation arises that requires interpretation. The loss of stability that occurs at this moment can be unsettling, or even threatening, particularly when the stakes are high. The multiple levels at which these controversies play out in interorganizational fields of action make it difficult to sort out how practices and institutional arrangements provide access to doubt. The rush to restore control is generated not only by the 'irritation of doubt' but also by the opportunities for reshaping the distribution of influence and resources among groups involved in the policy process (Laws and Rein, 2003: 175).

While situations of stability require continuous routine operations of ordering practice, in situations of crisis and controversy much more work is required to establish order. Controversies provide the opportunity for other practices of ordering to be introduced and become relevant. Prevailing practices need to be adjusted to the situation and justified anew. In other words in situations of controversies we can more easily see practices at work, as actors are forced to justify what 
they are doing. Justification means that texts and representations of why a distinct practice should be used are produced. In taking the justificatory texts and representations as a key source and investigating how controversies are settled and closed we can learn more easily about the background knowledge of practices.

Several kinds of crises or controversies can be identified. A crisis moment is to be seen as associated with the introduction of a new practice, a new representation, a new technology, a new object, a critical encounter between practices, or a new participant to a practice. The uncertainty of the new element introduced will cause the participants to reflect on how to proceed, whether to integrate the element at all and if so how, and how to naturalize it in a way that it becomes an integral part of the practice. Conflict notably arises when practices are not mutually sustainable (Schatzki, 2005: 474). The strategy of crisis and controversies hence implies first identifying these critical moments and then studying how actors deal with these situations, how they justify what needs to be done, and how they proceed to act and adjust practices or invent new ones.

\section{Following objects}

A third strategy employed by praxiography is that of tracing artefacts, in the form of objects and technologies but also in the format of language artefacts, such as concepts or metaphors. Artefacts of this type can be crucial containers of practice. Certain ways of doing and handling things are often 'inscribed' into an artefact. The research process can hence be initiated by a detailed study of an artefact followed by the observation of how it is used and an interpretation of which practices are inscribed in it. Such an approach to the complexity and mulitsitedness of practice can be called the ethnography of the object (or 'objective ethnography') as it follows an object across spaces. This will imply to reconstruct the activities that were required to bring it about by following the object backwards in time, visiting the sites of its manufacture and speaking to the actors whose relations were required. But it also means following the object forwards in time and tracing how it is used in various contexts and how its quality as a carrier of practice is maintained.

The ways that artefacts can provide access points to decipher practice are manifold. A first case concerns technologies. In a seminal study, for instance, De Laet and Mol (2000) investigated how a water pump designed to improve water safety in developing countries spurred unexpected forms of usage and was made part of a different set of practices once it travelled to Zimbabwe. While this is an illustration from a development policy context, the study of international politics will involve technologies which make the global. Examples include information technology spurring practices such as public diplomacy, or weapons technology and related practices of deterrence, non-proliferation or containment and control. Nuclear technology is one example (Pouliot, 2010), but also more recent technology such as smart phones and drones.

A second type of artefact is the document. Documents may be electronic (e-mails, PDF files, or Word documents), piles of loose or stapled paper, soft cover and 
hardcover documents or even illustrated books. Documents are artefacts that are shipped, flown or sent around the planet via post or electronic media. Documents are circulated to reach different sites. Large organizations are highly dependent on circulation to ensure the flow of information between various sites. Physically disconnected sites - an office around the corner, an office in a different continent and time zone, a library, an archive, or assemblies and court rooms - become connected by documents. At such sites documents are sometimes read, sometimes processed, sometimes admired, sometimes shelved, and sometimes immediately discarded. Then they become sorted, classified and stored in dusty archives and libraries. Once their life span has come to an end they are destroyed or eventually recycled and turned into new documents and books, or, if less fortunate, into cartons and park benches.

Documents are a core material in policymaking (Freeman and Maybin, 2011). They are crucial in organizational life (Putnam and Cooren, 2004). They are one of the main artefacts in international negotiations (Riles, 2006) and regional integration processes (Walters, 2002). Hence, they belong to the very basic material out of which the field of political practice is made. They are basic glue by which people relate to each other and organize their activities.

A further type of artefact is the linguistic construct, including concepts or metaphors. Concepts are more than signifiers. They are part of practices and using them allows for different forms of action. For instance, following concepts such as Human Security or Peacebuilding allows for the observation of new types of practices. This includes planning and coordination practices. As shown in Bueger and Bethke (2013), investigating concepts such the Failed State reveals a wide set of practices through which actors relate, transform their behaviour and compete over authority. The strategy of following objects then suggests we identify one or several objects and trail their connections backwards and forwards in time.

\section{Summary}

The three praxiographic research strategies are means to cope with the problem of interpreting background knowledge, to transcend scale and to cope with the complexity of practice. All three are strategies of looking down, they aim at paying attention to the incoherence and complexity of local situations, yet without losing sight of producing knowledge about practice which is telling and relevant to understand larger formations. Clearly these strategies are not exclusionary; one can blend these strategies into each other. A prime example of praxiographic research that blends the three described research strategies into each other is the work of Iver Neumann (2007). Neumann used the time he worked as an advisor in the Norwegian ministry of foreign affairs to study the practice of speech writing. Since his task at the ministry was speech writing, this put him in the ideal situation to understand what is required to write a speech in a ministry and which implicit knowledge it relies on. He studied a (structure-making) site: the ministry of foreign 
affairs in which Norwegian foreign policy is 'made'. He studied how the controversy of what should be in a speech and what not was settled. And finally he followed an object, the speech document, and investigated how it was circulated within and beyond the ministry.

\section{Praxiographic methods: strategies for data collection}

Praxiography draws on three principle means of data collection to interpret and reconstruct background knowledge: participant observation, document analysis and (expert) interviews. Participant observation is the preferred and primary method, since it allows for direct access to the body movements and actions that perpetuate a practice. Yet, the majority of praxiographers relies heavily on the two latter tools to circumvent the intricacies of participant observation. Praxiography is hence best seen as a mix of the three methodological techniques. All three methods are well established in political and social sciences. Praxiography and its interest in practice, however, gives these methods, as discussed in the following, a distinct twist and change in focus.

\section{Participant observation}

To some degree participant observation is the corresponding method of praxiography (Reckwitz, 2008: 196). Participant observation allows direct recordings of bodily movement either using field protocols or audio and video recording devices. Observing with eyes centrally allows for recording practices which do not entail speech. Consider the practice of remaining silent, or of using artefacts. It allows for grasping the regularity and orderliness of bodily movements. Participant observation is however not only observation, but also participation. Participation in a practice allows learning the implicit knowledge that underpins a practice. Through this process and the use of reflexive technologies such as field notes, praxiographers can explicate implicit meaning. Whether the focus is on a distinct site (which implicates to spend some considerable amount of time at a single site), on disputes (which requires to observe in practice how actors attempt to settle a controversy) or on tracing objects (which implies to conduct participant observation at several sites), participant observation is the pivotal means to understand practice.

Major studies in praxiography draw on participant observation. The seminal works of laboratory studies have carried out extensive participant observation. Others have investigated practices such as legal practice through an extended field visit to a court (Latour, 2010), parliamentary practice by observing the work of European parliamentarians (Wodak, 2009) or financial trading practices through participant observation in trading rooms (e.g. Knorr Cetina and Brugger, 2002).

Participant observation is however a demanding research technology, it requires considerable logistics (such as organizing a lengthy field stay), may put the researcher at a high professional, social, or physical risk (e.g. field research in conflict zones), and it is resource intensive and implies significant time and often 
considerable financial investments. Moreover, it reaches its limits if access to the field is problematic, for instance, if the researcher faces cultures of secrecy. Participant research moreover researches the practices 'here and now'. If the interest is in historical practices, participant research is insufficient, the researcher simply comes too late, the materiality of practice, the bodily movement is already gone (Reckwitz, 2008). Hence while participant observation will remain the primary method of praxiography, many praxiographies need to be based on other methods. Here I discuss two: qualitative (expert) interviews and textual analysis.

\section{(Expert) interviews}

Interviews about practices and their underlying knowledge are not the practices themselves. Indeed the method of interviewing has often been criticized to provide primarily ex-post rationalizations of an individual actor's behaviour which are worthless as data sources. Yet interviews can be an important mean to unravel the implicit structures of meaning and this is the reason they are widely used. To use interview generated data in a productive way it is important to clarify the relation between the interviewee and the practice of interest as well as to carefully consider what types of data are produced in an interview situation and how they can be interpreted.

An interview situation is an interaction between two persons (the researcher and the interviewee), that in praxiography has the purpose to explicate background knowledge. In selecting interviewees and the interview situation, it is important to clarify the relation of the interviewee to the practices that one wants to understand. We can distinguish two types of interviewees: (1) someone is or has been participating in the practice on an everyday basis; (2) or someone has spent a considerable amount of time in observing the practice. In both cases we assume that the interviewee is an expert in the practice.

In the first case the interlocutor is an expert because he has been participating in the practice under study. In this case we will ask the interviewee about the details of a practice in following for instance the 'interview to the double' procedure suggested by Nicolini (2009). This entails reconstructing the interviewee's detailed everyday actions and underlying evaluative standards. We ask how the interviewee performs certain activities that are part of the practice. And we will attempt to receive data with which knowledge, motivations, or emotional states the practice is performed. In this process, the interviewee is forced to explicate his implicit knowledge. Since an interview is usually carried out in a dialogue, the interviewer and the interviewee re-construct meaning together; they co-produce an interpretation of practices.

In the second case, we consider someone an expert for a practice because he has spent a considerable amount of time in understanding the practice. Such an expert can be a fellow specialized researcher, but also a journalist, a biographer, or an activist. Rather than asking such an interviewee for details of a practice and turning implicit knowledge into explicit, in such interviews we seek assistance in the 
interpretation process, and will ask questions of the type "why do you think that they are doing it in this or that way'?

Both types of interviewees can assist in reconstructing implicit knowledge. In interview situations those two types often become blurred, since a participant is also often an observer, and we might be interested in his descriptions of bodily movements and his implicit knowledge as well as in his observation-based interpretation of such knowledge. Yet it is important to keep in mind that the data collected and hence the types of questions differ. Type one practitioner questions help to collect raw data, and co-produce first interpretations, while type two observer questions concern (often already settled) interpretations. Hence in interviews the praxiographers can gather three types of data and interpretation, (1) detailed first hand descriptions of bodily movements, activities, utterances, or handlings of things, (2) explicated or interpreted meanings co-produced in the interview situation, (3) (second-hand) interpretations of implicit knowledge based on observations of the interviewee. Notably since the second type of data involves a crisis moment since the interviewee is forced to explicate what usually stays hidden, it is worth considering structuring or sequencing an interview in the order of the types of data the praxiographer is after.

Interviews have been widely employed in praxiography. Interview transcripts are frequently used in praxiography to give a voice to the practitioners. For instance in his study of administrative practice Wagenaar (2004) adopts a style of writing in which he uses lengthy passages from interviews in which administrators speak, which he in turn interprets. Studies, such as Pouliot's (2010) praxiography of the NATO-Russia Council or Andersen and Sending's (2010) study of the practices of implementing the concept of 'ownership', are examples from international politics which primarily draw on interviews. In many political science studies, the interviewees' voices remain however fairly hidden, in that the language of the practitioners is only randomly used.

\section{Documents}

A third type of data gathering in praxiography is the analysis of documents. Documents entail often important hints on practices and implicit knowledge. Documents are more than texts and different types of documents need to be distinguished since they give different types of clues about practice.

First, a major type of document for praxiography is manuals and handbooks that provide guidance on how to carry out activities. It goes without saying that the descriptions in manuals are not the same as the practices themselves. A fashion catalogue tells us fairly little about the practices of fashionistas; a research handbook hardly tells us about research practice, and likewise the manual of a laptop tells us little about how such a device is actually used. Nonetheless, manuals and handbooks can give us important clues about practices and the knowledge that informs them. Interpreting these documents implies taking a reflexive stance towards the idealized character of the instructions provided and their silences and limitations. 
Second, many practitioners produce documents in which they describe their practices and why they acted in this or that way. These self-descriptions and egodocuments come in the form of auto-biographies, letters or activity reports and will require the consultation of archives. They can assist in understanding what kinds of practices have been carried out and provide interpretations of the underlying background knowledge. If manuals and handbooks provide collectivized idealizations, ego-documents contain individualized and often heroic narratives, a fact that requires reflexivity.

A third type of document is visual artefacts, in the form of video, photography, art, or paintings. These are artefacts which document practices in that they give us representations of activities, body movements and the handling of objects. Notably videos published online, such as those on the youtube platform, can allow for important second-hand observations. Finally, also material documents such as architecture, houses, or city design can give important clues about a prevailing practice, since they have been designed for use and enable certain types of behaviour.

It is important to note that documents of such character require to be read as documents which relate to a bodily material practice which is outside of the text itself, but to which the text is related. For praxiographers such documents provide hints and clues about practices and their implicit meaning. They are not the meaning in itself.

While the majority of praxiographers makes use of documents in one way or the other, a telling example of how documents can be used to reconstruct practices is the work of Thomas Hausschild (2005). Hausschild studies practices of organized crime and terrorism. Terrorist practices, such as suicide bombing, are a paradigmatic example revealing that even under conditions in which participant observation or interviews are impossible praxiography can provide telling insights. Hausschild interprets practices by studying terrorism guidebooks and the videotapes that terrorist organizations such as Al Quaeda have left behind. Hausschild's case is revealing in that a praxiography might indeed be based exclusively on documents, should other forms of data generation not be feasible.

\section{Conclusion}

In this article I set out to understand and elaborate on the 'practice of doing practice theory driven research'. My argument was that the idea of turning to practice has always been not only a theoretical project, but also an empirical one. Practice theory implies developing distinct research approaches that provide for a meaningful 'search and find strategy', a form of reconstruction and a way of dealing with empirical material. The term 'praxiography' signifies this project and clarifies that practice theory implies being not only reflexive towards the practice one studies, but also the practices of research one engages in. The turn to practice places a heavy burden on empirical work. A genuine methodological discourse for how to conduct this work is needed. The practice turn in political science and international relations has neglected this debate so far and has mainly prioritized theory. While empirical 
studies are produced, a 'methodological muddling through' prevails. This is problematic as it disconnects theory from what it wants to understand: practice. To avoid that the unique advantages of practice theory get lost in the process of carrying out empirical work, methodological reflexivity is needed.

Praxiography is an approach that wants to reconstruct meaning and hence follows an interpretative and qualitative research tradition. Yet, praxiography entails a unique style of doing analysis and it requires coping with a set of distinct problems. I foregrounded the challenge of interpreting background knowledge, the problem of scales, as well as the problem of routine and change. These are intricate challenges, yet, a range of strategies and corresponding methods provide particular ways of coping with these. Yet, I do not want to suggest that these considerations provide a finite set of answers. As Nicolini (2009: 196) reminds us, 'because of its multifaceted and complex nature, practice can never be captured by a single method or reproduced through one single style of writing'. My discussion attempted to provide guidelines or 'rules of thumb' for how praxiography can be planned and carried out. A praxiographer will however have to blend his or her own mix of strategies and methods in his or her unique research context. Methodological concerns need to be addressed explicitly. The reflexive methodological discourse on how practices can be studied and how one can write about them will remain vital to the practice theoretical project.

\section{Acknowledgements}

For comments on earlier versions of this paper I am grateful to Frank Gadinger, Friedrich Kratochwil, Dvora Yanow, the participants in the workshop 'Anthropology meets International Relations', Frankfurt, November 2012, as well as the three anonymous reviewers of EPSR. Research for this article has been supported by the Economic and Social Research Council [ES/K008358/1] and the University of Copenhagen's Centre of Advanced Security Theory (CAST).

\section{References}

Abrahamsen, R. and M.C. Williams (2009), 'Security beyond the state: global security assemblages in international politics', International Political Sociology 3(1): 1-17.

Adler, E. and V. Pouliot (2011), 'International practices', International Theory 3(1): 1-36.

Adler, E. and V. Pouliot (eds) (2012), International Practices, Cambridge: Cambridge University Press.

Andersen, M.S. and O.J. Sending (2010), Governmentalization of Sovereignty: Ownership in Peacebuilding. Oslo: Norwegian Institute of International Affairs.

Aradau, C., J. Huysmans, A. Neal and N. Voelckner (eds) (2014), Critical Security Methods: New Frameworks for Analysis, London: Routledge.

Bourdieu, P. (1977), Outline of a Theory of Practice, Cambridge: Cambridge University Press.

Bueger, C. and F. Bethke (2013), Actor-Networking the Failed State - An Enquiry into the Life of Concepts', Journal of International Relations and Development, advance online publication, 18 January 2013; doi:10.1057/jird.2012.30.

Bueger, C. and F. Gadinger (2008), 'Praktisch Gedacht! Praxistheoretischer Konstruktivismus in den Internationalen Beziehungen', Zeitschrift für Internationale Beziehungen 15(2): 273-302. 
Collier, S.J. and A. Ong (eds) (2005), Global Assemblages. Technology, Politics and Ethics as Anthropological Problems, Malden, MA; Oxford, Carlton: Blackwell Publishing.

De Laet, M. and A. Mol (2000), 'The Zimbabwe bush pump: mechanics of fluid technology', Social Studies of Science 30(2): 225-263.

De Volo, L.B. and E. Schatz (2004), 'From the inside out: ethnographic methods in political research', PS: Political Science \& Politics 37(2): 267-272.

Eckl, J. (2008), 'Responsible scholarship after leaving the veranda: normative issues faced by field researchers and armchair scientists', International Political Sociology 2(3): 185-203.

Franke, U. and R. Weber (2012), 'At the Papini hotel: On Pragmatism in the Study of International Relations', European Journal of International Relations 18(4): 669-691.

Freeman, R. (2007), 'Epistemological bricolage: how practitioners make sense of learning', Administration \& Society 39(4): 476-496.

Freeman, R. and J. Maybin (2011), 'Documents, practices and policy', Evidence \& Policy: A Journal of Research, Debate and Practice 7(2): 155-170.

Freeman, R., S. Griggs and A. Boaz (eds) (2011), 'The practice of policy making', Evidence \& Policy: A Journal of Research, Debate and Practice 7(2): 127-136.

Golsorkhi, D., L. Rouleau, D. David Seidl and E. Eero Vaara (eds) (2010), Cambridge Handbook of Strategy as Practice, Cambridge: Cambridge University Press.

Guggenheim, M. (2012), 'Laboratizing and delaboratizing the world : Changing sociological concepts for places of knowledge production', History of the Human Sciences 25(1): 99-118.

Hajer, M.A. and H. Wagenaar (eds) (2003), Deliberative Policy Analysis. Understanding Governance in the Network Society, Cambridge: Cambridge University Press.

Halfon, S. (2006), 'The disunity of consensus: international population policy coordination as sociotechnical practice', Social Studies of Science 36(5): 783-807.

Hausschild, T. (2005), 'Auf den Spuren von Al-Qaida. Scheichs, Lügen, Videos: Eine Ethnographie des Terrors', Internationale Politik 2005(11): 32-51.

Hellmann, G. (ed.) (2009), 'The forum: pragmatism and international relations', International Studies Review 11(3): 638-662.

Howarth, D. (2009), 'Power, discourse, and policy: articulating a hegemony approach to critical policy studies', Critical Policy Studies 3(3): 309-335.

Keohane, R. and J. Goldstein (eds), (1993), Ideas and Foreign Policy. Beliefs, Institutions, and Political Change, Ithaca: Cornell University Press.

Knorr Cetina, K. (1995), 'Laboratory studies. The cultural approach to the study of science', in S. Jasanoff, et al. (eds), Handbook of Science and Technology Studies, Thousand Oaks: Sage Publications, pp. 140-166.

- (1999), Epistemic Cultures. How the Sciences Make Knowledge, Cambridge: Harvard University Press.

- (2005), 'Complex global microstructures: the new terrorist societies', Theory, Culture \& Society 22(5): 213-234.

Knorr Cetina, K. and U. Brugger (2002), 'Traders' engagement with markets: a postsocial relationship', Theory, Culture \& Society 19(5-6): 161-185.

Kratochwil, F. (2007), 'Of false promises and good bets: a plea for a pragmatic approach to theory building (the Tartu lecture)', Journal of International Relations and Development 10(1): 1-15.

Kratochwil, F. and J. Friedrichs (2009), 'On acting and knowing: how pragmatism can advance international relations research and methodology', International Organization 63(3): 701-731.

Kwa, C. (2002), 'Romantic and baroque conceptions of complex wholes in the sciences', in J. Law and A. Mol (eds), Complexities: Social Studies of Knowledge Practices, London: Duke University Press, pp. 23-52.

Latour, B. (1987), Science in Action. How to Follow Scientists and Engineers Through Society, Cambridge, MA: Harvard University Press.

- (2005), Reassembling the Social. An Introduction to Actor-Network Theory, Oxford/New York: Oxford University Press.

- (2010), The Making of Law. An Ethnography of the Conseil d'Etat, Oxford: Polity Press.

Lave, J. and E. Wenger (1991), Situated Learning: Legitimate Peripheral Participation, Cambridge: Cambridge University Press.

Law, J. (2003), Ordering and Obduracy, Lancaster: Centre for Science Studies, Lancaster University. 
- (2010), 'The double social life of method'. Paper presented at the 6th Annual CRESC conference on the Social Life of Method, 31 August-3 September, St Hugh's College, Oxford.

Laws, D. and M. Rein (2003), 'Reframing practice', in A. Maarten, M.A. Hajer and H. Wagenaar (eds), Deliberative Policy Analysis. Understanding Governance in the Network Society, Cambridge: Cambridge University Press, pp. 172-208.

Lidskog, R. and G. Sundqvist (2002), 'The role of science in environmental regimes: the case of LRTAP', European Journal of International Relations 8(1): 77-100.

Luyd, B. (2008), 'Centres of calculation and unruly colonists: the colonial library in Singapore and its users, 1874-1900', Journal of Documentation 64(3): 386-396.

Mackay, J. (2007), 'State failure, actor-network theory, and the theorisation of sovereignty', BSIS Journal of International Studies 3: 59-96.

Marcus, G.E. (1995), 'Ethnography in/of the world system: the emergence of multi-sited ethnography', Annual Review of Anthropology 24: 95-117.

Miettinen, R., D. Samra-Fredericks and D. Yanow (2009), 'Re-turn to practice: an introductory essay', Organization Studies 30(12): 1309-1327.

Mol, A. (2002), The Body Multiple: Ontology in Medical Practice, Durham and London: Duke University Press.

(2010), 'Actor-network theory: sensitive terms and enduring tensions', Kölner Zeitschrift für Soziologie und Sozialpsychologie 50(1): 253-269.

Neumann, I.B. (2002), 'Returning practice to the linguistic turn: the case of diplomacy', Millennium: Journal of International Studies 31(3): 627-651.

— (2007), “A Speech That the Entire Ministry May Stand for', or: Why diplomats never produce anything new', International Political Sociology 1(2): 183-200.

Nicolini, D. (2009), 'Articulating practice through the interview to the double', Management Learning 40(2): 195-212.

- (2013), Practice Theory, Work \& Organization, Oxford: Oxford University Press.

Nicolini, D., S. Gherardi and D. Yanow (2003), 'Introduction: toward a practice-based view of knowing and learning in organizations', in D. Nicolini, S. Gherardi and D. Yanow (eds), Knowing in Organizations. A Practice-Based Approach, Armonk, NY: M. E. Sharpe, pp. 3-31.

Nullmeier, F. and T. Pritzlaff (2009), 'Zu einer Theorie politischer Praktiken', Österreichische Zeitschrift Für Politikwissenschaft 38(1): 7-22.

Ortner, S.B. (1984), 'Theory in anthropology since the sixties', Comparative Studies in Society and History 26(1): 126-166.

Pouliot, V. (2010), 'The materials of practice: nuclear warheads, rhetorical commonplaces and committee meetings in Russian - Atlantic relations', Cooperation and Conflict 45(3): 1-17.

— (2007), “Sobjectivism': toward a constructivist methodology', International Studies Quarterly 51(2): 359-384.

Putnam, L.L. and F. Cooren (2004), 'Alternative perspectives on the role of text and agency in constituting organizations', Organization 11(3): 323-333.

Reckwitz, A. (2002), 'Toward a theory of social practices: a development in culturalist theorizing', European Journal of Social Theory 5(2): 243-263.

Reckwitz, A. (2008), 'Praktiken und Diskurse. Eine sozialtheoretische und methodologische Relation', in H. Kalthoff, S. Hirschauer and G. Lindemann (eds), Theoretische Empirie. Zur Relevanz qualitativer Forschung, Frankfurt a. M.: Suhrkamp Verlag, 188-209.

Riles, A. (2006), '[Deadlines]: removing the brackets on politics in bureaucratic and anthropological analysis', in A Riles (ed.), Documents: Artifacts of Modern Knowledge, Ann Arbor: University of Michigan Press.

Rouse, J. (1987), Knowledge and Power: Toward a Political Philosophy of Science, Ithaca: Cornell University Press.

— (1996), 'Engaging science', How to Understand its Practices Philosophically, Ithaca: Cornell University Press.

Sandholtz, W. (2008), 'Explaining international norm change', in W. Sandholtz and K. Stiles (eds), International Norms and Cycles of Change, Oxford: Oxford University Press, pp. 1-26. 
Schatzki, T.R. (2002), The Site of the Social. A Philosophical Account of the Constitution of Social Life and Change, University Park: Pennsylvania State University Press.

- (2005), 'Peripheral vision: the sites of organizations', Organization Studies 26(3): 465-484.

Spiegel, G.M. (ed.) (2005), Practicing History. New Directions in Historical Writing after the Linguistic Turn, New York: Routledge.

Srnicek, N. (2010), 'Conflict networks: collapsing the global into the local', Journal of Critical Globalisation Studies 2(2): 30-64.

Tsing, A. (2005), Friction. An Ethnography of Global Connection, Princeton and Oxford: Princeton University Press.

Vrasti, W. (2008), 'The strange case of ethnography and international relations', Millennium: Journal of International Studies 37(2): 279-301.

Wagenaar, H. (2004), “Knowing' the rules: administrative work as practice', Public Administration Review 64(6): 643-656.

Walters, W. (2002), 'The power of inscription: beyond social construction and deconstruction in European integration studies', Millennium: Journal of International Studies 31(1): 83-108.

Widmaier, W.W. and M. Blyth (2007), 'Exogenous shocks or endogenous constructions? The meanings of wars and crisis', International Studies Quarterly 51(4): 747-759.

Wodak, R. (2009), The Discourse of Politics in Action: Politics as Usual, Houndmills, Basingstoke/ New York: Palgrave Macmillan. 